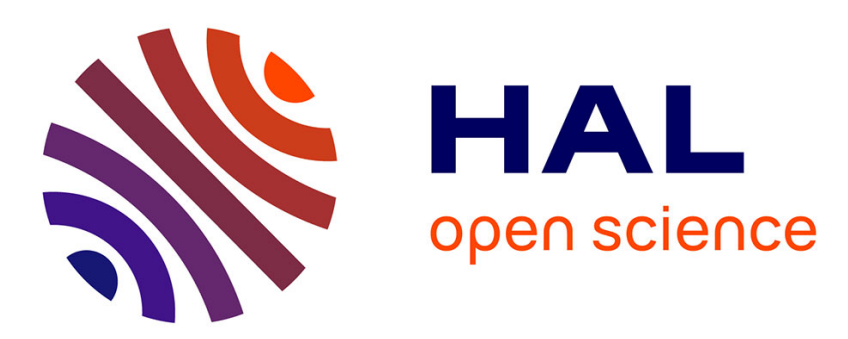

\title{
The identification and quantification of ketohydroperoxides and derived species produced during fuel low-temperature oxidation
}

Frederique Battin-Leclerc

\section{- To cite this version:}

Frederique Battin-Leclerc. The identification and quantification of ketohydroperoxides and derived species produced during fuel low-temperature oxidation. International conference on physics and chemistry of combustion and processes in extreme environments (Comphyschem'20-21) and VI International summer school "Modern quantum chemistry methods in applications", 2020, Samara, Russia. pp.020001, 10.1063/5.0034827 . hal-03443755

\section{HAL Id: hal-03443755 \\ https://hal.science/hal-03443755}

Submitted on 23 Nov 2021

HAL is a multi-disciplinary open access archive for the deposit and dissemination of scientific research documents, whether they are published or not. The documents may come from teaching and research institutions in France or abroad, or from public or private research centers.
L'archive ouverte pluridisciplinaire HAL, est destinée au dépôt et à la diffusion de documents scientifiques de niveau recherche, publiés ou non, émanant des établissements d'enseignement et de recherche français ou étrangers, des laboratoires publics ou privés. 


\title{
The Identification and Quantification of Ketohydroperoxides and Derived Species Produced During Fuel Low-Temperature Oxidation
}

\author{
Frédérique Battin-Leclerc \\ Laboratoire de Réactions et Génie des Procédés, CNRS - Université de Lorraine, ENSIC, \\ 1 rue Grandville 54001 Nancy, France
}

Corresponding author: frederique.battin-leclerc@univ-lorraine.fr

\begin{abstract}
Since 2010, photoionization mass spectrometry (PI-MS) coupled to jet-stirred reactor (JSR) has allowed to make notable progress in the detection and quantification of ketohydroperoxides, the key species for engines autoignition and fuel low-temperature oxidation. Significant advances in the understanding of the chemistry related to ketohydroperoxides has also followed the simultaneous detection of carboxylic acids and diones. Recent work has shown that PhotoElectron PhotoIon COincidence (PEPICO) technique combined with first principle computations, consisting in the determination of adiabatic ionization energies and the Franck-Condon envelope of the photoionization spectra, can be applied for identifying isomers through the energy analysis of the correlated photoelectron during fuel low-temperature oxidation. Using this last technique has also helped refining ketohydroperoxide quantification though a better understanding of their fragmentation pattern.
\end{abstract}

\section{INTRODUCTION}

The chemistry of the low-temperature gas-phase oxidation of fuel components is important in internal combustion engines and for the safety of industrial hydrocarbon oxidation processes (see Figure 1 (left panel)).
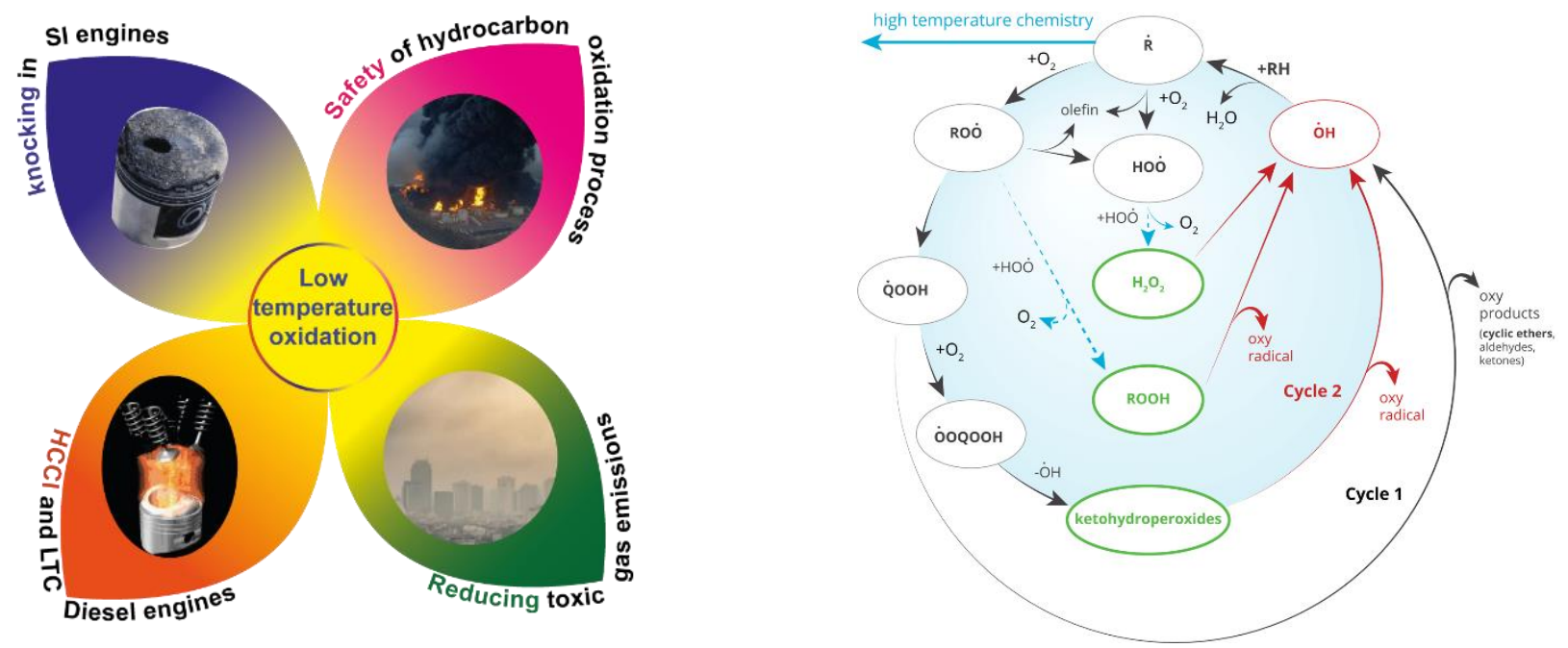

Figure 1. Schematic of main reactions in currently accepted models of alkane low-temperature oxidation (right panel (1)) and applied fields where this chemistry is of importance (left panel). 
This chemistry, which occurs from 500 to about $900 \mathrm{~K}$, is related to anti-knock characteristics crucial in sparkignited engines, to auto-ignition properties of importance for the development of newly proposed homogeneous charge compression ignition (HCCI) or low-temperature combustion diesel engines, and to the prediction of the emissions of toxic pollutants, such as aldehydes.

As reviewed by Wang et al. (1) and shown in Figure 1 (right panel), hydroperoxides, and particularly ketohydroperoxides (KHP), are at the heart of the chemistry of fuel low-temperature oxidation. The fragility of the $\mathrm{O}-\mathrm{OH}$ bond of KHP makes it easy to be broken involving the production of two new radicals, leading to a high reactivity of alkanes even at temperature as low as $550 \mathrm{~K}$. This important role of KHP explains why a large effort has been made to detect them. The work that I made in these directions with the help of many collaborators is summarized in the two following parts. It was performed through experiments performed in JSRs involving first the use of PI-MS, and more recently of PI-MS-PEPICO.

\section{PROBING KETOHYDROPEROXIDE CHEMISTRY BY PI-MS COUPLED TO A JSR}

Despite KHP have been included in the kinetic models ever since the pioneering work of Sahetchian et al. (2) in 1991, the experimental confirmation of their formation under conditions related to those found in engines was not given before the work of Battin-Leclerc et al. (3) in 2010. Using molecular beam, this Nancy-Hefei collaboration coupled a JSR to synchrotron radiation PI-MS of the National Synchrotron Radiation Laboratory (see figure 2 (left panel)) and used it to probe the oxidation of $n$-butane at temperature between 500 and $650 \mathrm{~K}$ under atmospheric pressure. Several $\mathrm{m} / \mathrm{z}$ corresponding to hydroperoxides were observed in the obtained mass spectra, especially $\mathrm{m} / \mathrm{z}$ 104 corresponding to the possible KHP produced from $n$-butane oxidation. As is shown in figure 2 (right panel), a photoionization efficiency (PIE) curve was also reported for $\mathrm{m} / \mathrm{z} 104$ in JSR experiments and the measured ionization energy of $\sim 9.3 \mathrm{eV}$ was shown in agreement with the value derived from ab initio theoretical calculations. In 2015, using also PI-MS technique, Eskola et al. (4) confirmed this measurement at the Advanced Light Source (the synchrotron at Lawrence Berkeley National Laboratory).
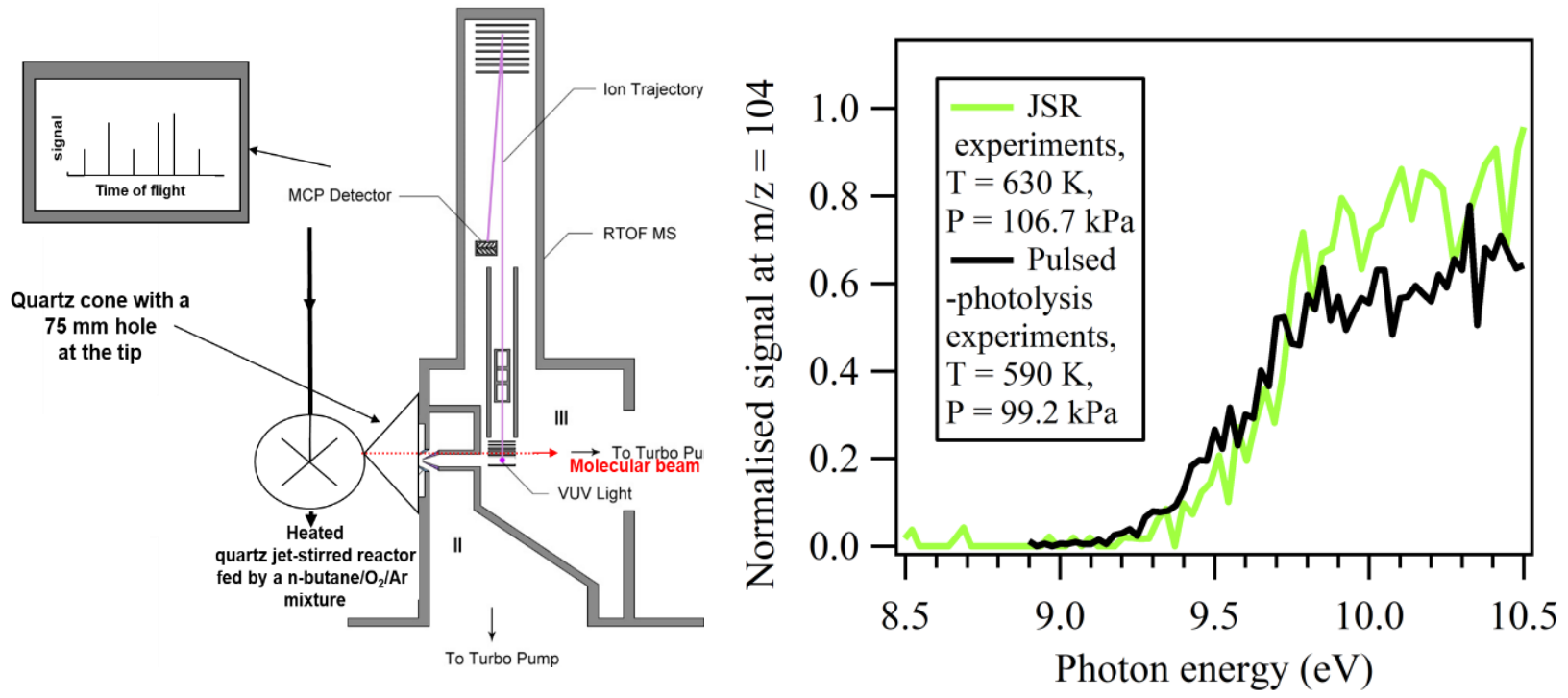

Figure 2. First coupling of a JSR with PI-MS detection: experimental device (left panel) (3), comparison between the measured PIE curves measured in JSR at Hefei (3) and by photolysis experiments at Berkeley (4).

Following that, KHP have been commonly detected during the oxidation of many hydrocarbons (e.g. $n$-pentane, hexane isomers, 1 -hexene, $n$-heptane, 2-methylhexane, 2,5-dimethylhexane, $n$-decane) and oxygenated fuels (e.g. acetaldehyde, $n$-butanal, dimethylether), together with a wide range of alkyl, alkenyl, and ketohydroperoxides (1). Products, which were not considered in kinetic models before, but which can derived from KHP were found to be 
formed in large amounts (5). This is the case of carboxylic acids, such as acetic and formic acid, and of compounds including two carbonyl functions, named diones $(5,6)$, the formation pathways of which are still to be understood (1).

Attempts have also been made for KHP quantification. Rodriguez et al. (6) used MS with both synchrotron and laser photoionizations to study hydroperoxide formation during n-pentane JSR oxidation. While this study reported that the obtained mole fractions were in good agreement with prediction from recent kinetic models for alkyl hydroperoxides, such as methyl and ethyl hydroperoxides, this was not the case for KHP for which an overprediction by a factor over 100 was observed (6). This deviation was attributed to the fragmentation of the KHP cation during MS analysis. In additions, the isomeric identification of KHP and diones could not be known from these PI-MS measurements. This has shown the ctitical need of a new technique to continue investigating hydrocarbon low-temperature oxidation.

\section{PROBING KETOHYDROPEROXIDE CHEMISTRY BY PI-MS PEPICO}

A new device coupling a JSR to PI mass spectrometer using the PEPICO technique has been built at the SOLEIL Synchrotron (see figure 3) and used to investigate the low-temperature oxidation of $n$-pentane by Bourgalais et al (7).

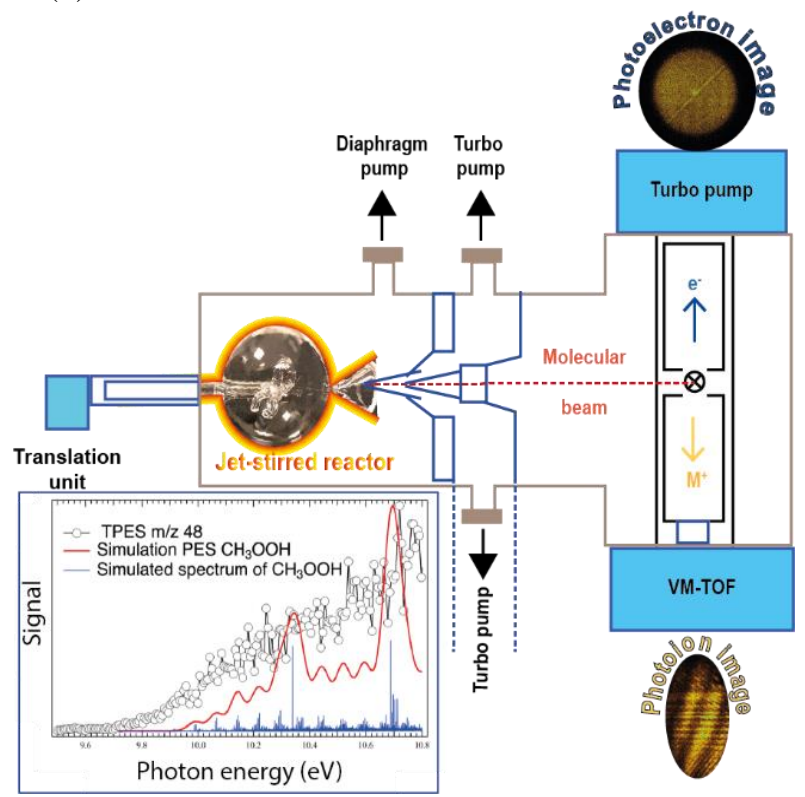

Figure 3. First coupling of a JSR with PI-MS-PEPICO detection: experimental device with JSR photo and example of mass-tagged photoelectron and photoion images recorded; insert: comparison between the measured Threshold PES (TPES) spectrum and the theoretically calculated PES related to methylhydroperoxide during $n$-pentane JSR oxidation at $606 \mathrm{~K}(8)$.
The used set-up, based upon the undulator-based DESIRS VUV beamline of synchrotron SOLEIL, is described in details in refs. $(7,8)$. This mass spectrometer is able not only to detect ions produced from the ionization events as that in Hefei, but also electrons in coincidence with the produced ions using the PhotoElectron PhotoIon COincidence (PEPICO) technique (9).

As is shown in the insert of Figure 3 for $m / 48$, PhotoElectron Spectrum (PES) on mass-selected compounds adds to the mass analysis provided by the PI-MS method a full electronic/vibrational fingerprint, specific of a given isomer. The measured TPES can be compared to literature ones for identifying the presence of usual species. This was done it (7) for a large number of species with $\mathrm{m} / \mathrm{z}$ from 28 to 84 . When PES data are not available, such as for cyclic ethers (m/z 86 in (7)) or for hydroperoxides, a comparison can also be made using simulated PES based on ab initio calculated Franck-Condon spectrum (10), this is of particular interest in the case of hydroperoxides, for which such spectra cannot be found in literature. In the case of methyl hydroperoxide $\left(\mathrm{CH}_{3} \mathrm{OOH}, \mathrm{m} / \mathrm{z} 48\right)$ produced during $n$-pentane oxidation (8), Figure 3 shows how the experimental TPES compared with the simulated ones and displays the related Franck-Condon spectrum.

By combining PEPICO measurements and high-level ab initio calculations, an attempt of identification was made for ketohydroperoxides and diones obtained from $n$-pentane oxidation (8). At $m / z \quad 100, \mathrm{C}_{5} \mathrm{H}_{8} \mathrm{O}_{2}$ isomers were identified and the analysis indicated the possible formation, in addition to diones, of species with a ketone and an enol function. Concerning $\mathrm{m} / \mathrm{z}$ 118, 4-hydroperoxypentan-2-one (named 2,4KHP, hereafter and displayed in Figure 4) was confirmed as the dominant obtained ketohydroperoxide, as predicted by detailed kinetic modeling using the model developed by Bugler et al. (11). Nevertheless, difficulties due to important fragmentation, as is discussed hereafter, has made impossible the identification of the ketohydroperoxides present in lower amounts. 
Another important point is that, due to the setting of the mass spectrometer, the peaks of ions, which can be attributed to a fragment, are more apparent in the obtained mass spectra than it was in those obtained in Hefei. Indeed, fragments exhibit broader peak shapes, while the parent ions appear as narrow peaks. This can well be seen in figure 4 for $m / z 43,57$ and 87. This is due to the lower extraction field, which renders the experiment more sensitive to the Doppler broadening caused by the kinetic energy release in dissociative ionization (8).

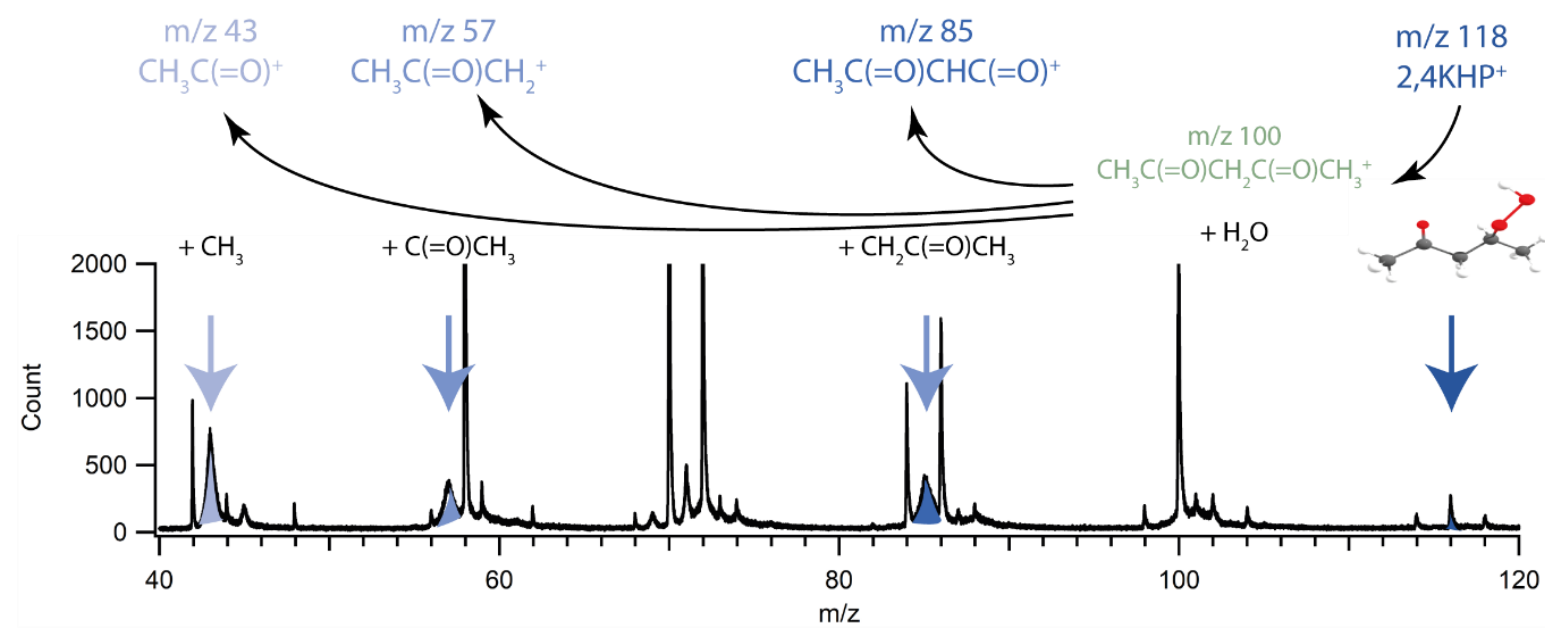

Figure 4. Mass spectrum obtained during $n$-pentane JSR oxidation with the fragmentation pathways proposed for 2,4KHP (reaction temperature of $606 \mathrm{~K}$ and PI energy of $10.0 \mathrm{eV}$ under the conditions of (8)). Blue filled peaks correspond to fragments.

The fact that these fragments correspond well to KHP was confirmed by energy and temperature dependence of the signals at $\mathrm{m} / \mathrm{z}, 118,85,57$ and 43. Considering that the fragments at $\mathrm{m} / \mathrm{z} 85,57$ and 43 derive from KHP fragmentation, the $2,4 \mathrm{KHP}^{+}$fragmentation patterns displayed in Fig. 4, which occurs via the formation of an unstable fragment at $\mathrm{m} / \mathrm{z} 100$, the same $\mathrm{m} / \mathrm{z}$ as diones, has been proposed.

In light of the fragmentation patterns shown in Figure 4, an attempt was made to refine the KHP quantification proposed by Rodriquez et al. (6) keeping their methodology. Since Moshammer et al. (12) quantified experimental KHP mole fractions in good agreement with modeling in the case of dimethyl ether, we used the same hypothesis as them. When fragmentation is considered, the signal value taken into account for mole fraction estimation should not anymore be only the single signal at $\mathrm{m} / \mathrm{z} 118$, but the sum of signals of the parent and all daughter ions. Figure 5 shows the four contributions, which should then be considered, and their contribution to the global KHP signal, with that at $\mathrm{m} / \mathrm{z} 85$ being the largest one and that at $\mathrm{m} / \mathrm{z} 118$ contributing for only $8 \%$.

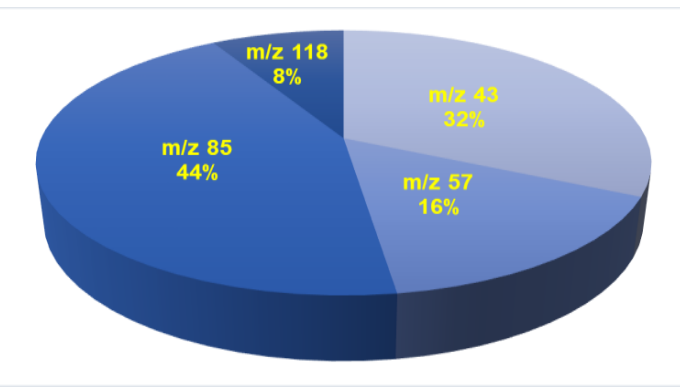

Figure 5. Contribution in the sum of the daughter and parent ion signal for KHP evaluated from to the signal heights in (6).

When the signal value at $\mathrm{m} / \mathrm{z} 118$ was revisited in this way and with also a more realistic value considered for the KHP cross-section, only a deviation of a factor of 3 was encountered between experimental and simulated KHP mole fractions. 


\section{CONCLUSION}

This paper describes some of the advances, which have been made for the identification and quantification of KHP and related compounds, acid and diones since 2010. The use of PI-MS and then PI-MS-PEPICO has allowed notable progress, but efforts has still to be made towards an accurate KHP isomeric identification and quantification, though fully understanding their fragmentation process and better estimating their PI cross-section. Furthermore, dione formation pathways have still to be elucidated.

\section{REFERENCES}

1. Z. Wang, O. Herbinet, N. Hansen, F. Battin-Leclerc, Prog. Energ. Combust. Sci. 73, 132-181. (2019).

2. $\quad$ K.A. Sahetchian, R. Rigny, S. Circan, Combust Flame 85, 511-514 (1991).

3. F. Battin-Leclerc, O. Herbinet, P.-A. Glaude, R. Fournet, Z. Zhou, L. Deng, H. Guo, M. Xie, F. Qi, Angew. Chem. Int. Ed. 49, 3169-3172 (2010).

4. A.J .Eskola, O. Welz, J. Zádor, A.O. Antonov, L. Sheps, J.D. Savee, D.L. Osborn, C.A. Taatjes, Proc. Combust. Inst., 35, 291-298 (2015).

5. O. Herbinet, F. Battin-Leclerc, S. Bax, H.L. Gall, P.-A. Glaude, R. Fournet, Z. Zhou, L. Deng, H. Guo, M. Xie, F. Qi, Chem. Chem. Phys. 13 (2011) 296-308.

6. A. Rodriguez, O. Herbinet, Z. Wang, F. Qi, C. Fittschen, P.R. Westmoreland, F. Battin-Leclerc, Proc. Combust. Inst. 36, 333-342 (2017).

7. J. Bourgalais, Z. Gouid, O. Herbinet, G.A. Garcia, P. Arnoux, Z. Wang, L.-S. Tran, G. Vanhove, M. Hochlaf, L. Nahon, F. Battin-Leclerc, Phys. Chem. Chem. Phys. 22, 1222-1241 (2020).

8. F. Battin-Leclerc, J. Bourgalais, Z. Gouid, O. Herbinet, G.A. Garcia, P. Arnoux, Z. Wang, L.-S. Tran, G. Vanhove, L. Nahon, M. Hochlaf, Proc. Combust. Inst. in press, (2021).

9. G.A. Garcia, H. Soldi-Lose, L. Nahon, Rev. Sci. Instrum. 80, 023102 (2009).

10. J.C. Poully, J.P. Schermann, N. Nieuwjaer, F. Lecomte, G. Grégoire, C. Desfrançois, G.A. Garcia, L. Nahon, D. Nandi, L. Poisson, M. Hochlaf, Phys. Chem. Chem. Phys. 12, 3566-3572 (2010).

11. J. Bugler, A. Rodriguez, O. Herbinet, F. Battin-Leclerc, C. Togbé, G. Dayma, P. Dagaut, H.J. Curran, Proc. Combust. Inst. 36 (2017) 441-448.

12. K. Moshammer, A.W. Jasper, D.M. Popolan-Vaida, Z. Wang, V.S. Bhavani Shankar, L. Ruwe, C.A. Taatjes, P. Dagaut, N. Hansen, J. Phys. Chem. A. 120, 7890-7901 (2016). 